\title{
Sex in older age in rural Malawi
}

\author{
EMILY K. FREEMAN $\dagger$ and ERNESTINA COAST*
}

\begin{abstract}
This paper examines how older adults living in rural Malawi explain and understand their sex lives. We present sex in this setting as a field in which broader understandings of ageing, aged identities, and conceptions of person- or adulthood in older age are played out and constructed. Qualitative data were collected from men $(\mathrm{N}=20)$ and women $(\mathrm{N}=23)$ aged $5^{\circ}$ to around 9o using in-depth multiple dependent interviews $(\mathrm{N}=135)$ between 2008 and 2010. The giving and receipt of sexual pleasure was considered natural and God-given. Primarily understood as a matter of 'power', sex was on the one hand, beneficial to older bodies, but on the other, not accessible to such bodies. Declining sexual frequency was associated with declining desire for sex, or frustration stemming from continued desire for sex. These discourses emerged from the way the ageing body was constructed as a weakened body, incompatible with understandings of adulthood based on physical productivity. Older men and women used sex to discursively respond to these challenges to their adulthood in two ways. Firstly, sex was used to confirm strength, physical productivity, and therefore, identity as an 'adult'. Secondly, adulthood itself was redefined as being based on moral, rather than physical productivity, and refraining from sex was used to demonstrate wisdom, self-control and therefore their 'adult' identity. Our results provide in-depth understanding of the ways constructions of ageing and sex can influence complex experiences of marital and non-marital sex in older age. We contribute to debates on sexuality in the gerontological literature by moving discussion beyond the presentation of continued sexuality as somehow exceptional or an indicator of successful ageing. Finally, in a setting of considerable HIV prevalence at older ages, our results challenge a preoccupation with fertility and chronological age in the collection of sexual health data in Africa.
\end{abstract}

KEY WORDS - ageing, sex, adulthood, identity, Africa, Malawi.

\section{Introduction}

A growing body of literature is addressing the absence of sexuality from gerontological research. However, despite widespread appreciation that

* Department of Social Policy, London School of Economics and Political Science, UK.

$\dagger$ Centre for Research on Ageing, University of Southampton, UK. 
sexuality is socially constructed and context-dependent (Dixon-Mueller 1993; Kellett 1991) most literature focuses on Western experiences (e.g. Gott and Hinchliff 2003; Schiavi 1999). Very little research has focused on sex in later life in Africa. Research on ageing in Africa tends to omit sexuality (e.g. HelpAge International and Africa Regional Development Centre 2001), understood to be an important element of human experience (Gagnon et al. 2002).

Among the limited attempts to understand sex at older ages in Africa, Freeman and Anglewicz (2012), King et al. (2010) and Todd et al. (2009) have quantified sexuality in terms of sexual partners and encounters, Gutsa (2011) and Owusu and Anarfi (2010) have qualitatively described some sexual behaviours, while Lee (1992), Nyanzi (2011) and van der Geest (2001) have offered in-depth ethnographic descriptions of sex and sexual experiences. Much of this work presents social and cultural norms that limit older adults' sexuality after childbearing (Gutsa 201 1; Nyanzi 201 1; Owusu and Anarfi 2010; van der Geest 2001).

In Ghana, van der Geest identified considerable censorship of sex at old age. Sex was considered incompatible with 'the beautiful image of old age' represented by the 'elder', a figure that showed restraint and control in all areas of life. Further, older respondents reported declining strength for sex. For men this was connected to general strength needed for courting, while for women, sex was a 'tiresome' physical task from which they derived minimal pleasure (van der Geest 2001). In contrast, Lee's 1960s research among the !Kung of Botswana documented increasing easiness of sexuality among post-menopausal women, including the initiation of sexual relationships with younger men outside marriage. Lee traces this to increasing leisure time and acceptance of extra-marital affairs that did not have resource implications for a woman's family. Nevertheless, only women aged $45^{-6} 5$ occupied this sexualised position; older adults were disregarded sexually (Lee 1992).

This body of African literature is limited in size, geographical coverage and scope. It typically describes sexuality at older age in isolation of social or cultural context, instead presenting evidence of continued sexual activity as somehow surprising (Gutsa 2011; Owusu and Anarfi 2010). Of the three studies that do situate sexual experiences, Nyanzi (2011) focuses exclusively on the experiences of widows in an urban setting, Lee (1992) documents social and sexual roles across the lifecourse but does not give voice to individual experiences or attitudes towards sex, and does not explore sexuality among women after age $6_{5}$ or among men, whilst van der Geest (2001) provides an impressionistic insight into sexuality at old age in Ghana.

In this study, the first substantive investigation into sex at older ages in Malawi, we argue that understanding sex at older age requires reflection 


\section{Emily Freeman and Ernestina Coast}

on the meanings of sexuality in the socio-cultural context of people's lives, as well as on experiences and understandings of 'being old'. Understanding the relationship between sex and older age involves recognising the influence of older adults' identities on the parameters of behaviour; what is (in)appropriate within the role connected to a particular identity. Understanding older adults' identities in turn requires explanation of the contexts within which the meanings that underpin them were created, and an appreciation of how those meanings, and therefore identities and behaviours, change over time.

This study examines in-depth meanings of sexuality and sexual behaviours at older age. We identify linkages between sexual meanings and behaviours by situating them within a model for understanding how older adults in a rural African setting negotiate ageing. This study contributes not just to a better understanding of sexuality in later life, but to a better understanding of ageing in Malawi.

\section{Methods}

Data were collected in rural Malawi, where over 90 per cent of the population aged $5^{\circ}$ and older live (National Statistical Office of Malawi 2008). The research presented here on sex at older age is part of a larger study exploring the experiences and meanings of old age, sexuality and HIV infection at older age. While this paper focuses exclusively on sexuality, the methodology refers to collecting data with this broader aim and the findings draw on our analyses of all the data collected.

The study used a constructivist grounded theory framework (Charmaz 2006, 2008). Data were collected from older adults living in Balaka district, southern Malawi, using in-depth interviews $(\mathrm{N}=135)$. These interviews constitute the main source of data and are the only data presented here. However their analysis was informed by analysis of interview data collected during a three-month multi-site pilot study $\left(\mathrm{N}=4_{2}^{2}\right)$, focus groups with older adults with HIV $(\mathrm{N}=3)$ and fieldwork observations.

Data were collected from men $(\mathrm{N}=20)$ and women $(\mathrm{N}=23)$ aged between $5^{\mathrm{O}}$ and around $90 \mathrm{using}$ repeated in-depth dependent interviews $(\mathrm{N}=13 \mathrm{O})$ between March 2009 and August 2009, with a median gap of one week between interviews. Intervals between interviews allowed time to reflect on data collected and develop a further interview guide. Collected over six months, these interviews do not reflect a longitudinal design but instead elicit a detailed and in-depth understanding of older adults' experiences. Between April 2010 and June 2010 further interviews $(\mathrm{N}=5)$ were carried out with five respondents interviewed in 2009. These interviews were used 
to explore how respondents' experiences had developed, and to verify the on-going analyses.

Questioning in repeat dependent interviews builds on data previously gathered from the respondent and increases data quality and the credibility of analytical interpretation. Here, benefits included: firstly, providing opportunity to discuss a wide range of research topics and the flexibility to follow-up on topics discussed so that important areas for investigation were not missed. Secondly, facilitating deeper understanding of respondents' perspectives and experiences by building narratives across multiple interviews in which interviewers could probe for further explanations, clarify complicated stories and resolve contradictions in our understanding. Thirdly, repeated dependent interviews gave respondents the opportunity to verify Freeman's understanding since previously discussed topics could be returned to and respondents asked whether their comments had been captured correctly, as well as their thoughts on her interpretation of what they had said and the links she had drawn between various issues.

Each respondent was visited between one (four respondents) and six times (one respondent), depending on their consent and availability, fieldwork logistics, and the research questions generated during our conversations. Most were visited three (18 respondents) or four (13 respondents) times for interview. Interviews typically lasted between 60 and 180 minutes. Additional occasional visits were made to respondents throughout the fieldwork period. These greetings, short conversations and observations contributed to rapport building and provided further context to the recorded conversations.

Interviews were conducted in Chichewa or Chiyao by Malawian research assistants fluent in both languages. These were audio-recorded, and transcribed and translated into English the following day by the interviewers, who were encouraged to add their thoughts on the interview. Transcripts were discussed to clarify meanings and debate the validity of interpretations. Translation is never straightforward and depends on the translator's linguistic ability, cultural understandings and local knowledge, understanding of the research, opinion as to what does and does not need explaining for the researcher, as well as their attitude towards the work. The final transcripts analysed here represent the best English the research assistants knew, supplemented by translation checking by Freeman using secondary resources.

The findings of cross-cultural qualitative research are not presented in respondents' 'own words' and the construction of the transcripts that become data is acknowledged (Maclean 2007; Mishler 1991; Temple 2005). Three steps were taken to produce transcriptions that reflected 


\section{Emily Freeman and Ernestina Coast}

the research conversations as much as possible and that, when read alongside research assistants' field notes and Freeman's observations, could be used to interpret respondents' words meaningfully. Firstly, subsequent interviews asked respondents whether what had been backtranslated was what they meant in the discussions. Secondly, when a theme or analytic idea was built around the reoccurrence of a particular word, care was taken to check that these words were accurate translations of what respondents said and did not simply reflect a particular research assistant's interpretation. Thirdly, a sub-sample of audio-recordings $(\mathrm{N}=6)$ were double-transcribed and translated by different research assistants and the emerging themes and meanings were compared. This suggested that the transcriptions produced in this study are good representations of the audio-recorded research conversations, confirming Hammersley's contention that although constructed, transcriptions are not 'made up' (Hammersley 2010).

Freeman met and spent time with all respondents. Previous research on similarly sensitive topics has warned against the presence of an outsider researcher during interviews (e.g. Coast 2006). However, pilot data collection in June to August 2008 indicated that respondents viewed local interviewers as an extension of the researcher (as noted elsewhere; Huygens et al. 1996). Interviewers reported that respondents were comfortable sharing their experiences, and during interviews respondents reported that they enjoyed the opportunity to explain their understandings to the younger local interviewers and to the foreign researcher. Contrary to the authors' expectations, the only discernible influence of Freeman's presence on the interview was the additional time needed for translation.

Since interviews were dependent on both an individual respondent's narratives and the themes and questions emerging from analysis of all collected data, interview topics and questions varied between respondents and over time. Interview conversations covered understandings and experiences of older age, family, giving and receipt of care, work, problems, illness, relationships, sexuality and HIV, and other topics. Respondents were only asked to quantify their behaviours (e.g. frequency of sexual contact) when it was salient to the experience they were reporting. The initial interview guide and a sample of anonymous dependent interview guides are available from Freeman. Although conversations were not 'life history interviews', increasing attention was paid to past experiences as data collection proceeded. Eliciting narratives on personal histories (such as past relationships and work) provided insight into the social context in which respondents constructed their aged and sexual identities and reported sexual behaviour. 


\section{Sampling}

The study was conducted under the auspices of the Malawi Longitudinal Study of Families and Health (MLSFH), a rural panel survey. The MLSFH is conducted in approximately 120 villages in three districts of Malawi, one in each of the three regions of the country (Anglewicz et al. 2009).

This study used a theoretical sampling strategy, connected to its analytical strategy in a cyclical process. Data collection was followed by analysis, which generated tentative ideas or 'categories' as well as further questions about those categories. Further data were collected to answer these questions and explicate the categories. This was done by sampling in a way that maximised variation in the categories so that they could be juxtaposed and examined (Corbin and Strauss 2008).

An initial sample for substantive data collection was drawn from the 2008 MLSFH Balaka district respondent listing. It was based on characteristics relating to categories theorised to be important from analysis of pilot data collected and review of relevant literature, and randomly drawn within those stratifications. These were HIV status, sex and age. Adults aged $5^{\circ}$ years and older were included in the study, based on the broader research questions concerning sex and HIV infection outside peak childbearing ages of $15^{-49}$ years, and life expectancy at birth in 2007 (when data collection was

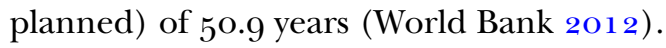

As data collection and analyses proceeded, categories were elaborated and refined, new questions were raised and new analytical categories developed. These were investigated by drawing further samples based on associated respondent characteristics. Subsequent analysis suggested the importance of familial transfers of support, HIV and understandings of health. These were investigated by drawing further samples that included polygamously married respondents, respondents within the same family, older members of two HIV support groups and two asing'anga (traditional healers).

Theoretical sampling is therefore cumulative (Corbin and Strauss 2008). As more data were collected and analysed, categories were explicated, relationships between categories were examined, questions became more specific and the categories and themes most important for shaping respondents' experiences became clearer. Data collection continued until the analytical concepts identified as being most salient for understanding these experiences were sufficiently well developed.

\section{Data analysis}

The procedure for qualitative data analysis was guided by those set out by Charmaz (2006) and Corbin and Strauss (2008), and adapted to suit the logistical and theoretical needs of collecting and analysing data in this 


\section{Emily Freeman and Ernestina Coast}

context. The process involved defining and indexing data using coding, producing analytical ideas about data, writing successive memos about the data, and sorting memos to produce an integrated analysis. A strategy of 'constant comparisons' was used at each analytic stage. It involved comparing data from different respondents' interviews, comparing data from a single respondent's interviews, and comparing data within and across codes, categories and, finally, memos (Corbin and Strauss 2008).

Following each interview, the transcripts and field notes were scrutinised line by line and further questions about issues discussed in that, and previous interviews, were recorded in an individual interview guide used during subsequent interviews. Memos were written about emergent perspectives, experiences and themes identified based on comparisons across respondents and within narratives of a single respondent across the interviews. These were discussed with research assistants and investigated in subsequent interviews with all respondents until other themes replaced them in the investigations.

After the period of substantive data collection in 2009, the researcher returned to open coding (Corbin and Strauss 2008) using NVivo data analysis software (QSR International 2008). Returning to all the data after the period of data collection to carry out what is typically regarded as the initial step in analysis is rare. Here it contributed to the sensitivity of analysis by facilitating re-examination of earlier interviews in light of the analytical ideas developed later during data collection and Freeman's increased familiarity with the cultural and linguistic context of Malawi.

Throughout the data collection and analysis process, findings were verified to ensure their credibility by asking respondents for their thoughts on emergent interpretations, constant re-evaluation of the data collected, and by subsequent checking of the dataset for data that did not fit into the explanatory models.

\section{Ethics}

Permission to conduct research was granted locally by village heads, the National Association of People Living with HIV/AIDS in Malawi (NAPHAM) and support group leaders, nationally by the National Health Sciences Research Committee (NHSRC) through the study's association with the MLSFH's health-related data collection, and internationally by the London School of Economics. Participation was voluntary and the purpose of the research was explained to each participant verbally and using printed information sheets. Respondents marked consent forms or gave audiorecorded verbal consent to participate. In line with both cultural norms regarding visitors and the precedent set by researchers in the study site, 
respondents were given gifts in recognition of their hospitality and time spent answering questions.

Three potential respondents, all sampled from the MLSFH dataset, declined to participate in the research without giving a reason. One respondent discontinued participation following her first interview, reporting that she was tired of taking part in research studies. Two further respondents died in the interval between substantive and further data collection in 2009 and 2010.

\section{Respondents}

No respondents lived entirely alone, all either living within the same compound or village as family members. Kinship in the research site is predominantly matrilineal and residence is matrilocal. Marriage and remarriage is common in Malawi (Kaler 2001; Reniers 2003). Most respondents had been married more than once, one respondent was married during the research period and several discussed re-marrying in the future. Three respondents were polygamously married.

\section{Findings}

Our analysis draws on evidence from respondents. We extend our reflections on their narratives by situating them against the broader literature. The quotations used (accompanied by socio-demographic information and pseudonyms) were selected to highlight the themes we present.

Conversations with older men and women yielded rich data in which the body was an underlying discourse and prominent in discussions of ageing and sex. How the body was socially constructed and constituted was central to how respondents understood what good sex entails, how they experienced old age and ageing, and how this relates to ideas of adulthood and identity. Analyses identified complex and apparently contradictory discourses about sex in older age both between respondents and within single respondents' narratives. We first discuss meanings and understandings of sex at older age, before exploring respondents' experiences.

\section{Understandings of sex}

Attitudes to sex in rural Malawi were positive; sex and sexual desire were natural and understood to be a necessary element of marital and non-marital romantic relationships. Sexual desire was considered to be innate in all people, and in principle, continue throughout the lifecourse. Those who did not desire sex were ill, or dead. 


\section{Emily Freeman and Ernestina Coast}

Although procreation featured in respondents' narratives, sex was much more frequently discussed in terms of pleasure and general wellbeing. Sexual pleasure was discussed by and for both men and women, who articulated the importance of 'sweetness' in sex. Men and women talked of the importance of pleasure through foreplay and through the movement of their bodies during intercourse. Respondents reported that men and women evaluateand disregard - lovers based on the sexual pleasure they delivered.

However, it was the timely mixing of compatible male and female ejaculate that was understood to be the essence of sexual pleasure - vital for achieving 'sweetness'. Although the importance of giving and receiving semen for healthy, pleasurable sex has been noted in other African settings (e.g. Bond and Dover 1997; Coast 2007; Holtzman 2011), data collected in rural Malawi emphases the importance of both male and female sexual fluids. Their significance is situated within a broader understanding of the lifegenerating and sustaining potencies in the body's fluids and blood in particular.

For respondents, all bodily fluids contained a life force, translated by all research assistants as 'power' or 'strength'. This life force was strongest in blood and in ejaculate, also referred to as 'blood' by many respondents. An individual's blood (of both types) was finite. The quantity and flow of these fluids around the body determined an individual's strength and vitality. In death the body was emptied of fluid:

$\mathrm{R}$ : The importance [of blood] is that it makes the body strong, but when you don't have adequate blood you are weak...

I: When talking about blood, are you talking about the actual blood, or semen or just power?

R: Those things all contribute to make strength ... Strength and blood go together ... Blood is strength. (Joseph, male, 6o, married)

Since ejaculate contained and partly constituted power, the exchange of ejaculate during intercourse represented the exchange of this power. Male and female ejaculate was considered to contain 'vitamins' and 'oils' for strength and health. Several metaphors in which sex was linked to eating and food reflect respondents' understanding of ejaculate as containing nourishment for the recipient:

This blood [ejaculate] is important. In nature, if your blood is good and your friend's [sexual partner's] is good, they come together, and you become fat and the skin looks good ... They look very healthy, their bodies become dibwiridibwiri [healthily fat] ... The man and the woman when they have sex, they exchange blood ... This blood, the man gives out sperm and also women give our strength. When they meet inside they form blood [power] inside ... You need to exchange the blood, for you two people to feel good. (Joyce, female, 68, single) 
The power stored in seminal and vaginal fluids was visible in its consistency: thicker fluids signalled potency, while 'watery' fluid was weaker, containing less power and vitamins. When men and women's fluids were powerful, and compatible, they mixed to produce blood inside a woman which became a baby.

Infecundity in women and men signalled a reduction in the quantity and power of their sexual fluids. Women who were infecund were described as being 'dry'. Some respondents understood infecund men and women, including post-menopausal women, to both give and receive less pleasure.

A second element constituting power and potency in the ethnophysiology of sex in rural southern Malawi was temperature. While Kaspin (1996), Marwick (1968) and Wolf (2001) have theorised a coherent Chewa understanding of corporeal temperature as culturally defined (or 'ritual') body states, in these data, 'hot' and 'cold' were used to denote a more diverse and less coherent range of states for both Chewa and Yao respondents. All stemmed from the temperature of the body's fluids, described as being hot or cold to reflect the potency of the life force contained within them.

Hot lovers were sexually and physically competent, reflecting both the quantity of their blood and the heat of the life force in their blood. Throughout the interviews, 'fire' was used to describe a sexually powerful man ('fireman') and the temperature of sexual fluids ('fire from the woman and a man meet'). Sex with cold lovers reflected their diminished life force and temperature. This sex was not usually as 'sweet' as 'hot' sex. The meeting and compatibility of warm, powerful and healthy blood during intercourse was associated with both reproductive potential and sexual pleasure. Davidson explained:

And there is blood [ejaculate] which corresponds well with the hotness of a person. Twice-twice [it matches]. And you know that if I continue with this one she will become pregnant... Then there is blood that when you make sex with her it's just like as if you have put [your penis] in water. It is very cold. You could even decide not to continue with her ... because your private parts also become cold. Because the coldness has come from inside her and to release [orgasm] you need to try harder ... (Davidson, male, eighties, recently married)

However, Davidson had finished childbearing and had recently married a 'dry' post-menopausal older woman (aged mid-seventies). He reported that he had married this particular woman precisely because he did not want to have more children. Nevertheless, Davidson considers himself to have an active and mutually satisfying marital sex life:

My wife sometimes says that if at my age I am managing to do like that, what about when I was a youth?! Because I ask her after having sex if she is satisfied. She says she is more satisfied and runs short of words. 


\section{Emily Freeman and Ernestina Coast}

As Davidson's narrative illustrates, rather than resulting in fertility, or involving any real fecundity, sex was pleasurable when it was only suggestive of the 'power' of one's sexual partner. Ideas about procreation and the transfer of healthy, powerful sexual fluids therefore remained relevant after childbearing and into very old age.

\section{Sex as a matter of strength}

Sexual potency was demonstrated by the vigour of sexual intercourse and the number of 'rounds' (orgasms) involved. Good sex therefore required both, an adequate supply of physical, bodily strength and a sufficient quantity and quality of bodily fluid ('blood') for pleasurable exchange. However, the ageing process was understood to gradually deplete men and women's bodily strength, as well as their finite store and flow of blood.

This decline was evidenced by, and embodied in, both the menopause and erectile dysfunction. The menopause was considered a sign from God that a woman does 'not have enough blood in [her] body, [she] has already lost a lot of blood' and therefore has no more blood to lose. Erectile dysfunction, on the other hand, was understood as evidence of the drying of blood in old age which, containing less life force, was not 'running normally', but instead congealing around and 'coating' the nerves in the groin.

In addition, sex itself was understood to 'use up' a person's physical strength, and the quantity of life force contained in the sexual fluids they released during intercourse. Every sex act depleted an individual's supply of sexual power further:

R: The blood comes out of you to the woman's body, yes ... [and] when you are having sex, it's when the blood comes out of the woman's body [to your body].

I: So does it mean that every day you have sex with a woman you lose blood?

R: Yes every day.

I: Or you lose the power of the blood?

R: The sperms which you produce, it is your blood ['life force']. That is why after releasing the sperms you become tired. (Lyson, male, 7o, married)

Old age was therefore conceptualised as a time of infecundity, drying and coolness. Old bodies were unhealthy bodies, described as 'not fresh', 'rotten' or 'of no use'. Although desire for pleasurable sex was considered innate and universal, old age limited the ability to act on these desires:

Some people are cold because of ageing, if they need a woman the body doesn't respond ... When a man has a desire for a woman, and he fails to make sex with her, there we say the hotness in that man is finishing ... [he's] cold. (Kondwani, male, mid-seventies, married) 
Respondents sought to manage the declines in 'power' they experienced. For some this involved balancing sex, or 'bed work', against other work tasks. Motivated to avoid dependency in later life, these respondents believed that it was more important to use limited strength for farming or housework than for sex:

People tire each other [through having sex]. The issue is dangerous. After sex if people are not strong, they cannot go to work in the farm the next morning, they will be tired. But those who are strong, they can do it and then go to the field ... We should say it is the old people who get tired more than the young people. (Amina, female, early seventies, single)

However, since sex was regarded to be pleasurable, this involved a difficult trade-off. Other narratives focused instead on preserving sexual abilities, noting that limiting 'bed work' for farm work went against human nature. These narratives oscillated between gaining strength from their partner's sexual fluids and losing the strength contained in their own, in order to either strengthen or prolong their sexual ability, respectively.

For some respondents, the 'vitamins' received from male and female sexual fluids became especially important in later life, as their strength-giving properties could compensate for some of that lost due to ageing. For Wema, having a sexual partner represented a successful old age since "when your sleep with your husband, you feel so fine because they share to you their blood which strengthens your body' (Wema, female, 56 , polygamously married). Having been strengthened by the 'vitamins' received and heat created during intercourse, respondents' sexual abilities were fortified:

R: Like me, I am only using my blood, the man's blood is no longer there, it is finished.

I: If you had a man, would your body have improved?

R: Yes ... I am saying the truth. I would have changed. If I had a man, we would have shared, your body you share with me, and I share mine with you. If we agree each other [arranged to have sex], you would have grown fat and I would have grown fat. So with a good [sexual] diet, people would say, there goes a woman. (Joyce, female, 68, single)

Other respondents however focused on stemming the loss of 'blood' from sex in older age. Male and female respondents discussed avoiding chiwerewere (illicit sex, in this case, outside marriage) in older age. There were a number of warnings about the dangers of chiwerewere, based on the loss of blood from increased sexual frequency that having an extra-marital partner was universally understood to involve:

Those who do much chiwerewere grow very old quickly ... Us old people, if we do much chiwerewere we finish very quickly ... If you don't want to look very old avoid sleeping with many men ... you will be finished. (Madalitso, female, sixties, newly married) 


\section{Emily Freeman and Ernestina Coast}

Other warnings, particularly for men, focused on the mixing of sexual fluids of different temperatures during intercourse. The commingling of these incompatible fluids was considered to be dangerous, causing the cooler partner's blood to weaken. In all cautionary tales reported, the extra-marital partner had hotter blood than the married participant.

For example, Davidson, discussed previously, was a sing'anga (healer). He reported seeing many men, usually while still in their forties, who having had chiwerewere, no longer had powerful blood. Their blood has been lost because their lovers were 'hungry' for sex, and subsequently released their dangerously hot sexual fluids before the men could release theirs to cool them:

But some women can kill a man, if you find someone who is sex hungry-who has stayed for a long time without sex. During sex she will be the first one to release her fluid before you release the sperm. You can become ill. After having sex with such a lady, he could even feel so much pain when passing out urine he could cry. Because she has released first, and a man needs to be the first [so that] when she is releasing you have already cooled her.

It was to avoid the dangers of losing strength in this way that Davidson reports getting married. Noting that 'if you are faithful you retain your strength', he presents marriage as a way of ensuring continued sexual pleasure ('freedom'):

I made up my mind to get a wife. So that we should be farming and getting food which we will be eating together. I didn't want to do chiwerewere because I am an old person and I would be finished. It was a way of caring for myself. I wanted freedom. (Davidson, male, eighties, recently married)

The emotional acceptance of declining sexual strength was more likely if a spouse had avoided chiwerewere throughout a lengthy relationship since the loss of 'power' could be conceptualised as the result of having shared bodily resources with in marriage. However, since sex was considered to be a necessary element of marriage, all respondents reported that sexual inability in older age would hinder developing or maintaining newer relationships. These discussions were frequently accompanied by citing the proverb that 'a man doesn't leave his home for [just for] nsima [the staple meal]', men and women each reporting that it was the opposite sex who would insist on sex. For example, Wilson's wife had died six years before we met. He had been married once, and unsuccessfully, since. Throughout our conversations he returned to the breakdown of that relationship, reporting to have been 'chased away' for 'failing to perform'. For him, erectile dysfunction made any future relationship impossible since 'the penis is the owner of the friendship [marriage]' (Wilson, male, mideighties, single). 


\section{Contrasting narratives of sexual desire}

Unlike sexual strength, universally understood to eventually decline in very old age, the data contain contrasting narratives regarding sexual desire. Our analyses show a relationship between narratives of sexual desire and those of sexual strength. For respondents who asserted that sexual desire was innate, it could not be diminished even in very old age, creating a source of frustration:

I: So grandfather how do you differentiate sex nowadays and sex those days?

$\mathrm{R}$ : There is a total difference.

I: How do you stay nowadays?

R: I struggle.

I: But you still want the sex?

R: Yes why not? A fisherman is always a fisherman.

[...]

I So is ageing good?

R: Ageing? Ageing is not good. We grow old but ageing is not good.

I: In future do you want to grow older than this?

R I don't want.

I: Why not?

R: I want to be having sex some other days.

I: You don't want to grow old because of that only?

R: Yes and some other tasks at home.

I: You also said that you are losing power as you are growing old.

R: Yes.

I: How does that affect you?

R: I am affected. I get annoyed this time because I am ageing. Yes I get annoyed ... I should be like a young person ... If it is dying, I should die at this stage [of ability]. (Lyson, male, 7o, married)

For respondents who reported declining desire for sex, declining sexual ability was forwarded as both a cause and consequence. These respondents, most of whom were without a sexual partner, reported having no sex, or having sex very rarely. On one hand, decreasing sexual frequency was a proactive response to declining sexual desire since 'to enjoy sex and feels its "sweetness" it means you put your whole heart in it'. On the other hand, declining sexual desire was a passive response to declining sexual frequency, since abstaining from heat-producing sex was widely understood to 'cool' a person. 


\section{Emily Freeman and Ernestina Coast}

\section{Experiences of sex}

Some respondents spoke of 'finishing' with sex, others of being still potent, while still others oscillated between each position across their interviews. Our analyses suggest that these sexual identities follow from, but also contribute to, respondents' understandings of older age and the way they negotiated changes to their identities as they aged. Two sexual narratives emerge that were aligned to two positive aged identities: that of capable adult and that of the respectable elder.

Sexual potency and the capable adult. The association between 'blood' and sexual ability aligned sex to a more general sense of productivity and contribution. This is neatly highlighted in the name for infecund men, gojo. The term translates as 'impotent' but also 'unproductive' more generally. Respondents' narratives alternated between discussing sexual and other physical limitations. Although some respondents, particularly unmarried women, reported being 'finished' sexually and instead were 'concentrating on farming', others, particularly married respondents, presented sexual ability as the 'final strength' - the behaviour that separates and distinguishes an individual from the very old and 'useless'. Men and women who could not perform sexually were regarded as being 'like children'.

Just as work was associated with physical and social productivity, the potential to give and receive sexual pleasure (implying some sense of reproductive productivity) was behaviour associated with the identity of a valid and alive person, that is, an adult. Further, it was tied to understandings of being a 'real' man or woman.

Here sociology's identity theory becomes a useful lens. According to the theory, an individual derives their social identity from the role they play within the social structure, based on the socially constructed shared meanings and expectations associated with that role and its performance, held in contrast to other roles (Burke and Tully 1977). These expectations form a set of 'identity standards' that guide behaviour so that 'in order to be (some identity), one must act like (some identity)' (Burke and Reitzes 1981: 9o). This process is reciprocal, so that individuals classify themselves as having a particular identity based on their behaviours, and individuals behave in ways that reinforce and confirm their identities. A role identity is arrived at when (a) an individual identifies with, and is committed to, a socially recognised category (the role), (b) others identify the individual as occupying that role, (c) an individual achieves gratification by performing in that role, and $(d)$ the demands of a particular situation make enacting the role socially appropriate and appreciated (McCall and Simmons 1966). To be an adult one must therefore act like an adult. Sexual activity - or at least, 
the potential for sexual activity - was regarded as 'acting like an adult'. It formed part of the adult identity standard. Conversely, behaviour that was understood to reflect sexual inability fell short of the adult identity standard. By limiting capacity for sexual activity, old age threatened an individual's identity as an adult. Our data suggest that this identity represented the core identity respondents associated with and aspired to.

Sexual restraint and the idealised adult. Despite linking sexual ability with the essence of living (being an 'adult'), limiting sexual activities was associated with being wise and 'cool'. Respondents talked of avoiding chiwerewere in older age. Although this ostensibly accords with previous research regarding appropriate sexual behaviour for older adults (e.g. van der Geest 2001), in rural southern Malawi, this did not reflect the much-documented idea of an asexual older age. Instead, our analyses indicate that it was the positive attitudes to sex at all ages and the health implications of chiwerewere outlined above that underpinned this position.

Chiwerewere was dominant in respondents' discussions of sex throughout the lifecourse and believed to be frequently practised at every age. Madalitso notes that 'Everything has its own food. Eyes see, a mouth has a tongue, teeth. Everything was created for its purpose so every part of the body should do its work. That's why some old men do much chiwerewere (laughs): some people attend to it [sex] very much, but others not' (Madalitso, female, sixties, newly married). Respondents' narratives reflect some degree of tolerance towards those who engaged in chiwerewere, and two respondents (male and female) candidly discussed their ongoing extra-marital relationships.

Nevertheless, there were a number of warnings about the dangers of chiwerewere in the data. Respondents reported that HIV, gonorrhoea and syphilis, as well as the receipt of hotter blood, could weaken an individual and would subsequently cause the loss of physical and sexual power. Sex with multiple partners was understood to be unwise, rather than socially unacceptable. Respondents reported limiting their sexual activity in light of physical, rather than social harm. This is a more nuanced situation of sexual control in older age than has been identified in previous studies.

Refraining from chiwerewere demonstrated wisdom and sagacity. It could only be achieved by a model adult: that of the 'elder'. For older men and women experiencing (or expecting to experience) changes in their sexual capabilities, and so struggling to maintain their identities as capable adults, the sexually restrained elder presented an alternative positive identity.

This identity recast a lack of sexual activity, or declining sexual frequency, within a discourse of wisdom and socially valued self-control. In doing so, ideas about what it meant to be an adult and what behaviours are associated with that identity shifted. The adult identity standard became dissociated 


\section{Emily Freeman and Ernestina Coast}

from the body and its sexual productivity. Instead it centred on acting in ways that could be considered 'morally productive'. In these narratives, it is chiwerewere, understood to be foolish behaviour, rather than sexual inability, that was referred to as being child-like.

\section{Sexual identity in old age}

Men and women reported behaviours that were compatible with the identities of the sexually capable or morally idealised adult. We argue that this reflects their motivation to maintain positive identities in face of the perceived threat posed by old age. This analytical position makes sense of and accounts for contrasting and sometimes contradictory reporting of behaviour between and within respondents' interviews.

To illustrate these presentations and explore how they were enacted by older men and women, we present two case studies, James and Tiwonge. They show most clearly the way respondents discursively produced positive identities during conversations about their experiences and expectations of growing old.

Stressing sexual potency: James. We met James sitting at his house alone: his six children and 102 grandchildren and great-grandchildren at school, their farms or resident elsewhere. Aged in his early eighties, he struggled to walk but still farmed. He was a pastor of a gospel church, a small mud building a few metres from his home.

Four years after the death of his first wife, James had remarried a younger woman in her fifties. The marriage was arranged by friends who sought a wife to assist him, and he agreed to the match because he 'had the [sexual] desire for a woman'. The marriage ended quickly and badly; James reported that 'she just wanted [his] money'. He left her, returned to his home and was thinking about marrying for a third time:

I: Suppose you have found the money you are looking for, will you find another woman and marry her?

R: Aaah, yes, very much so. Very much so, very sure.

I: There are other people who say that, when a person becomes old, sexual relationships are not important. What about you?

R: (Laughs) It is the way one is born. It's one's strength. It depends on the person's strength. Some still want to have it [sex], but others don't, they just stay ... My strength has not gone down. (Interview 1)

R: There are two types of old age: the first one is where you do not have a desire for a woman, that's being old, then you are finished. There is another type where you still have a desire for a woman, it means you are not old yet. (Interview 2) 
In 2010, six months after our last (and third) interview, we visited James again to find out if he had made enough money to find and support a new wife. He had died at the end of 2009.

Across three interviews James continually reasserts his virility and power. He is explicit about his sexual capabilities, forwarding these in ways that are compatible with the productive adult identity. He offers no prediction of declining bodily strength or life-force in his blood, noting that he will marry again in the following year. James was motivated to discursively align his (potential) behaviour with the behaviour held as standard for the identity of the 'powerful' sexually productive adult.

Stressing wisdom and sexual restraint: Tiwonge. Tiwonge, 20 years younger than James, lived with his wife in the heart of his village. Across our five interviews with him, Tiwonge's narratives oscillated between his declining sexual strength and subsequent frustration, and his demonstration of selfrestraint and wisdom in older age:

I: That day you said that the heart never ages but//

R: (Respondent interrupts to finish the sentence) //the body ages ... Because the heart, when you stay you think, you see a girl with good breasts. The heart thinks that had it been the past this girl, I could have slept with her. But because I have aged, you see that the body has aged but not the heart ... It is painful because you think, 'aha'. You think of doing such a thing but the body fails ... So a person like me, even if I see the girls I just admire and it ends there. Had it been not for my age (trails off) $[\ldots]$

I: What qualifies one to be an old person?

$\mathrm{R}$ : It is first that person accepts the situation that he is aged, because there some aged people who behave like children. Like children, look at that old man he is busy with girls. That is not [old age]. But when you accept yourself and start behaving like an aged person, stop doing some other things. Sometimes you are tempted even at old age, but you have to reason to be out of such situations.

$[\ldots]$

I: You said it's good to be careful with women as an aged person, can you tell me more on this?

$\mathrm{R}$ : Yes it is possible, it is possible if you reason and know that I am not supposed to do this because I am an aged person, because at times it happens that you are not of the same age and energy. When having sex when you are not energetic enough, you become a fool to that child. So you say I don't have to look like a fool. Do you get me? I am aged, I will look like a fool, because by the time you produce sperms it happens that 


\section{Emily Freeman and Ernestina Coast}

the girl is tired of the sex. And sometimes you are even told that since that time you are failing to release sperms so you look like a fool so it's better to take yourself as an aged person, do you get me? (Interview 2, Tiwonge, male, 63, married)

Although Tiwonge reports declining sexual potency, like James he presents a positive identity. By directing each conversation away from behaviour that is not compatible with the sexually productive adult identity and towards behaviour that is compatible with the idealised, morally productive adult identity, Tiwonge is able to circumnavigate the negative identity of the 'possible self' (Markus and Nurius 1986), here the person empty of 'blood', and close to death.

Both James and Tiwonge maintained positive identities in which they were able to present themselves as valid people-adults capable of productive or moral contribution. In doing so they were able to avoid the feared social imaging of a dependent, useless, child-like old age. In our analyses, sex is considered as a platform on which these age identities are both played out and constituted. For older men and women in this study therefore, sex was both, an essential - and pleasurable - part of their lived experiences, and a salient part of how they understood and experienced growing old.

\section{Conclusion}

This research is one of very few in-depth examinations of sexuality in later life in Africa. Our data shed light on how older men and women in rural Malawi explain and understand their sex lives. Sex is a field in which broader understandings of ageing, aged identities and conceptions of personhood in older age are both played out and constructed.

Primarily understood as a matter of strength, sex was, on one hand, beneficial to weakened older bodies, but on the other, not accessible to such bodies. Declining sexual frequency was associated with declining desire for sex, or frustration stemming from continued desire for sex. We have drawn links between these competing discourses by situating them within the understandings of ageing and adulthood in this setting.

The ageing body was constructed as a weakening, failing body. It was incompatible with the adult identity, defined by a set of behaviours that were understood as being sexually productive. However, despite experiencing declining body strength and sexual ability, no respondents identify with the adult identity's corresponding opposite - that of the child: a 'non-person'.

Instead, we identified two responses to the dissonance between sexual behaviour and the desired identity. The first can be considered as an attempt to realign perceptions of (potential) sexual behaviours so that they fit with 
the adult identity as sexually productive. The second indicates a gradual shifting in respondents' understandings of what it means to be an adult, away from sexual production towards moral production, demonstrated by behaviours such as wisdom and sexual restraint. By forwarding these compatible moral behaviours, respondents aligned themselves with this alternative positive identity. This is a more nuanced situation of socialsanctioning of sex at old age than found in previous studies, and one that does not inadvertently perpetuate the much-cited stereotype of 'asexual old age' (Scherrer 2009).

There are two main limitations to the data presented here. The first concerns the difficulty of defining who is an 'older' person. Sampling used chronological age. However, as identified in both African (Cliggett 2005; Cohen and Menken 20o6; Tengan 2002) and non-African settings (Featherstone and Hepworth 1989), data collected suggested that chronological age was of less significance than socially constructed age for respondents. As a result, data were collected about the experiences of some adults who do not self-define as 'older'. This situation is clearly incompatible with the study's aim to reflect respondents' concerns. To respond to this challenge, respondents' non-chronological definitions of age were used in the analysis and little attention was given to the chronological age of respondents. The approximations of chronological age used alongside quotations are presented for the benefit of the reader. Almost all sexuality data pertaining to 'adults' collected in African settings by international researchers use chronological ages $15^{-49}$ as an inclusion criteria. By using the same chronological age criteria in this study, we were able to represent the experiences of adults who are generally underrepresented in African data.

Secondly, data were mainly collected from older adults. In doing so we missed perspectives from other actors which would have allowed comparison and contextualised older adult's experiences. This was partially addressed during data collection by speaking to younger adults in and around the sampled villages and the younger representatives of organisations concerned with care for older adults in Malawi. These conversations informed our analyses. This was further addressed in the analysis by regarding respondents' narratives as situated and personal perspectives that may not be shared by non-respondents.

Although the findings cannot be generalised to all older men and women in rural Malawi, they do provide an in-depth understanding of the ways constructions of ageing and sex can influence complex experiences of sexuality in older age. Since levels of divorce and remarriage are high in the sample (Nyanzi 2011), the data presented here also offer an opportunity to consider experiences of sexuality beyond and outside marriage. 


\section{$113^{8}$ Emily Freeman and Ernestina Coast}

Further, we respond to recent criticism of writing on sex in old age which has focused on asserting continued sexuality and subsequently positioned sexual disinterest as negative or as evidence of unsuccessful ageing (Scherrer 2009). In this paper we explore and account for these alternative, less-sexualised positions, giving them much needed voice within the nascent debates on sexuality in the gerontological literature.

The understandings of sexuality presented here have important policy implications given HIV prevalence of 8.9 and 5.4 per cent among men and women aged $5^{\mathrm{O}-6} 5_{5}$ in rural Malawi (Freeman and Anglewicz 2012). Firstly, the findings challenge the preoccupation with fertility and chronological age in the collection of sexual health data in Africa by highlighting sexual activity within and outside long-term relationships at advanced ages. Secondly, our data indicate the importance of seminal fluid exchange for healthy, pleasurable sex for women and men. This finding deepens our understanding of barriers to condom use at older age, previously expected only to involve women's difficulty negotiating condom use when their contraceptive value is redundant (Williams and Tumwekwase 2001). Thirdly, this research emphases the continued importance of pleasure as a motivation for sex at older ages. In doing so it accords with previous research among younger adults in Malawi (e.g. Morris 2000; Tavory and Swidler 2009) and middle-aged women in Bostwana (Lee 1992) and urban South Africa (Orner 2005), but, along with the focus on the importance of foreplay in respondents' narratives, offers a sharp contrast to research focused on sex at older ages in Ghana (van der Geest 2001). However, sexual enjoyment remains largely absent from policies and interventions to reduce HIV infection (Gosine 2005, Philpott, Knerr and Maher 2006). Monitoring and evaluation of HIV prevention efforts in Malawi have recognised the lack of advice on how to have pleasurable safer sex and recommended that pleasure is included in dissemination of advice on practical skills for HIV prevention (United Nations General Assembly Special Session 2010). We suggest that prevention efforts must not only include older adults, they must include older adults' sexual pleasure.

Beyond this focus on sexuality and the implications for sexual health policies, the research illustrates that the identification of societal-level understandings of older age do not imply a set of behaviours older adults themselves identify with and adhere to. In order for adequate policies and programmes to be developed with regard to old age and ageing in Africa, more research is needed to uncover the nuances of older adults' lived experiences of ageing. There is a need for more qualitative and mixedmethod research to understand the quantified behavioural data that do exist for older people in Africa, as well as the inclusion of older adults themselves in policy and programme formulation. 
Finally, given the importance of context highlighted in this study, future research might usefully consider sexuality in older age in contrasting African countries and settings. In particular, research might concentrate on experiences in urban areas in countries in which the pace of urbanisation, a key driving force of change in the region, is rapid.

\section{Acknowledgements}

We are grateful to all study participants for their openness and hospitality. The logistical and intellectual support of those working on the Malawi Longitudinal Studies of Families and Health in the collection of data used in this paper is very gratefully acknowledged. The research would not have been possible without the help of Malawian research assistants Jonathan Kandodo, Violet Boillo, Aminah Wadi, Pretorius Halidi and Tommy Navilembo. Special thanks is given to Jonathan Kandodo for on-going support and discussion of lives of older adults living in Malawi. The research presented here was approved by the London School of Economics and through the Malawi Longitudinal Study of Families and Health, the National Health Sciences Review Committee in Malawi. Emily Freeman received funding from the UK Economic and Social Research Council to conduct the research (ES/Fo22174/1). She received additional funding to analyse collected data from the London School of Economics. Neither financial sponsor played a role in the design, execution, analysis and interpretation of data, or writing of the study. Emily Freeman is the key author. Both authors have made substantial contribution to: (a) the conception and design, or analysis and interpretation of data; (b) the drafting of the article or revising it critically for important intellectual content and (c) approval of the version to be published. The authors have no conflict of interest.

\section{References}

Anglewicz, P., Adams, J., Obare, F., Kohler, H.-P. and Watkins, S. 2oog. The Malawi Diffusion and Ideational Change Project 2004-o6: data collection, data quality, and analysis of attrition. Demographic Research, 2o, 21, 503-40.

Bond, V. and Dover, P. 1997. Men, women and the trouble with condoms: problems associated with condom use by migrant workers in rural Zambia. Health Transition Review, 7, supplement, S377-91.

Burke, P. J. and Reitzes, D. C. 1981 . The link between identity and role performance. Social Psychology Quarterly, 44, 2, 83-92.

Burke, P. J. and Tully, J. C. 1977. The measurement of role identity. Social Forces, 55, 4, 881-97.

Charmaz, K. 2006. Constructing Grounded Theory: A Practical Guide Through Qualitative Analysis. Sage, London.

Charmaz, K. 2008. Grounded theory in the 21 st century: applications for advancing social justice studies. In Denzin, N. K. and Lincoln, Y. S. (eds), Strategies of Qualitative Inquiry. Sage, Los Angeles, 203-41.

Cliggett, L. 2005. Grains from Grass: Aging, Gender, and Famine in Rural Africa. Cornell University Press, Ithaca, New York.

Coast, E. 2006. Local understandings of, and responses to, HIV: rural-urban migrants in Tanzania. Social Science E् Medicine, 63, 4, 1000-10. 


\section{Emily Freeman and Ernestina Coast}

Coast, E. 2007. Wasting semen: context and condom use among the Maasai. Culture Health E' Sexuality, 9, 4, 387-401.

Cohen, B. and Menken, J. A. (eds) 20o6. Aging in Sub-Saharan Africa: Recommendations for Furthering Research. National Academies Press, Washington DC.

Corbin, J. M. and Strauss, A. L. 2008. Basics of Qualitative Research: Techniques and Procedures for Developing Grounded Theory. Sage, Los Angeles.

Dixon-Mueller, R. 1993. The sexuality connection in reproductive health. Studies in Family Planning, 24, 5, 269-82.

Featherstone, M. and Hepworth, M. 1989. Ageing and old age: reflections on the postmodern life course. In Bytheway, B., Keil, T., Allatt, P. and Bryman, A. (eds), Becoming and Being Old: Sociological Approaches to Later Life. Sage, London, 143-57.

Freeman, E. and Anglewicz, P. 2012. HIV prevalence and sexual behaviour at older ages in rural Malawi. International Journal of STD $\mathcal{E}^{2}$ AIDS, 23, 7, 490-6.

Gagnon, M., Hébert, R., Leclerc, G. and Lefrançois, R. 2002. Development and validation of a sexual actualization measuring instrument for the elderly. Educational Gerontology, 28, 7, 62 1-33.

Gosine, A. 2005. The Power of Pleasure. IDS Working Paper, Institute of Development Studies, Brighton.

Gott, M. and Hinchliff, S. 2003. How important is sex in later life? The views of older people. Social Science $\mathcal{E}$ Medicine, 56, 8, $1617-28$.

Gutsa, I. 2011 . Sexuality among the elderly in Dzivaresekwa district of Harare: the challenge of information, education and communication campaigns in support of an HIV/AIDS response. African Journal of AIDS Research: AJAR 10, 1, 95-100.

HelpAge International and Africa Regional Development Centre 2001. Research and Information on Ageing in Africa: An Annotated Bibliography. HelpAge International, London.

Hammersley, M. 2010. Reproducing or constructing? Some questions about transcription in social research. Qualitative Research, 10, 5, 553-69.

Holtzman, J. 2011 . The thinness of bulls: food, sexuality and masculinity in Samburu, Northern Kenya. Paper presented at ECAS 2011: $4^{\text {th }}$ European Conference on African Studies: African Engagements: On Whose Terms?, $15^{-1} 8$ June, Uppsala.

Huygens, P., Kajura, E., Seeley, J. and Barton, T. 1996. Rethinking methods for the study of sexual behaviour. Social Science E Medicine, 42, 2, 224-31.

Kaler, A. 2001. 'Many divorces and many spinsters': marriage as an invented tradition in southern Malawi, 1946-1999. Journal of Family History, 26, 4, 529-56.

Kaspin, D. 1996. A Chewa cosmology of the body. American Ethnologist, 23, 3, $561-78$.

Kellett, J. M. 1991. Sexuality of the elderly. Sexual and Marital Therapy, 6, 2, 147-55.

King, O., Issacb, O., Ademolab, A. and Nnennad, I. 2010 . Condom use and perceived HIV infection among geriatrics aged $65^{-102}$ years in Nigeria. Outliers, 3, Spring. Available online at http://www.irnweb.org/assets/articles/King_et._al_._HIV_ Infection_Among_Geriatrics_.pdf [Accessed 10 October 2011].

Lee, R. B. 1992. Work, sexuality and aging among!Kung women. In Kerns, V. and Brown, J. K. (eds), In Her Prime: New Views of Middle-aged Women. University of Illinois Press, Urbana, $35^{-48 .}$

Maclean, K. 2007. Translation in cross-cultural research: an example from Bolivia. Development in Practice, 1 7, 6, 784-90.

Markus, H. and Nurius, P. 1986. Possible selves. American Psychologist, 41, 9, 954-69.

Marwick, M. G. 1968. Notes on some Cewa rituals. African Studies, 27, 1, 3-14.

McCall, G. J. and Simmons, J. L. 1966. Identities and interactions. Free Press, New York.

Mishler, E. G. 1991. Representing discourse: the rhetoric of transcription. Journal of Narrative and Life History, 1, 4, 255-80.

Morris, B. 2000. Animals and Ancestors: An Ethnography. Berg, Oxford. 
National Statistical Office of Malawi 20o8. Population and Housing Census Data Tables. International Food Policy Research Institute (IFPRI), Zomba, Malawi.

Nyanzi, S. 2011. Ambivalence surrounding elderly widows' sexuality in urban Uganda. Ageing International, 36, 3, 378-40o.

Orner, P. 2005. Sexuality of older women. Paper presented at the Africa Region Sexuality Resource Centre Understanding Human Sexuality Seminar Series, 16 September, Cape Town.

Owusu, A. Y. and Anarfi, J. K. 2010. Sexuality of the aged and people with disability: challenging popular folkways. Research Review of the Institute of African Studies, 26, 1 , $61-80$.

Philpott, A., Knerr, W. and Maher, D. 2006. Promoting protection and pleasure: amplifying the effectiveness of barriers against sexually transmitted infections and pregnancy. The Lancet, 368, 9551, 2028-31.

NVivo qualitative data analysis software; QSR International Pty Ltd. USA. Version 8, 2012.

Reniers, G. 2003. Divorce and remarriage in rural Malawi. Demographic Research, special collection 1, $175^{-206 .}$

Scherrer, K. S. 2009. Images of sexuality and aging in gerontological literature. Sexuality Research and Social Policy, 6, 4, $5^{-12 .}$

Schiavi, R. C. 1999. Aging and Male Sexuality. Cambridge University Press, Cambridge.

Tavory, I. and Swidler, A. 20og. Condom semiotics: meaning and condom use in rural Malawi. American Sociological Review, 74, 2, 17 1-89.

Temple, B. 2005. Nice and tidy: translation and representation. Sociological Research Online, 10, 2. Available online at http://www.socresonline.org.uk/10/2/temple. html [Accessed 12 November 2012].

Tengan, A. 2002. Social categories and seniority in a house-based society. In Makoni, S. and Stroeken, K. (eds), Ageing in Africa: Sociolinguistic and Anthropological Approaches. Ashgate, Aldershot, UK, 43-66.

Todd, J., Cremin, I., McGrath, N., Bwanika, J. B., Wringe, A., Marston, M., Kasamba, I., Mushati, P., Lutalo, T., Hosegood, V. and Zaba, B. 20o9. Reported number of sexual partners: comparison of data from four African longitudinal studies. Sexually Transmitted Infections, $\mathbf{8}_{5}$, supplement $\mathbf{1}, \mathrm{i} 72-80$.

United Nations General Assembly Special Session 2010. Malawi HIV and AIDS Monitoring and Evaluation Report: 2008-2009. Geneva, Switzerland.

van der Geest, S. 2001. 'No strength': sex and old age in a rural town in Ghana. Social Science Ẽ Medicine, 53, $1383-96$.

Williams, A. and Tumwekwase, G. 2001. Multiple impacts of the HIV/AIDS epidemic on the aged in rural Uganda. Journal of Cross-cultural Gerontology, 16, 3, $221-36$.

Wolf, A. 2001. AIDS, morality and indigenous concepts of sexually transmitted diseases in southern Africa. Africa Spectrum, 36, 1, 97-107.

World Bank 2012. World DataBank (BETA). Available online at http://databank. worldbank.org/Data/Home.aspx [Accessed 29 May 2012].

Accepted 6 December 2012 ; first published online 5 March 2013

Address for correspondence:

Emily Freeman, Centre for Research on Ageing,

University of Southampton,

Southampton Sol 7 1 BJ, UK.

E-mail: E.K.Freeman@soton.ac.uk 